\title{
Effect of Surfactants on Association Characteristics of Di- and Triblock Copolymers of Oxyethylene and Oxybutylene in Aqueous Solutions: Dilute Solution Phase Diagrams, SANS, and Viscosity Measurements at Different Temperatures
}

\author{
Sanjay H. Punjabi, ${ }^{1}$ Nandhibatla V. Sastry, ${ }^{1}$ Vinod K. Aswal, ${ }^{2}$ and Prem S. Goyal ${ }^{3}$ \\ ${ }^{1}$ Department of Chemistry, Sardar Patel University, Vallabh Vidyanagar 388 120, Gujarat, India \\ ${ }^{2}$ Solid State Physics Division, Bhabha Atomic Research Center, Mumbai 400 085, India \\ ${ }^{3}$ UGC-DAE Consortium for Scientific Research, Mumbai Center, Mumbai 400 085, India
}

Correspondence should be addressed to Nandhibatla V. Sastry, nvsastry_17@rediffmail.com

Received 7 March 2011; Revised 29 June 2011; Accepted 7 July 2011

Academic Editor: Jan-Chan Huang

Copyright (C) 2011 Sanjay H. Punjabi et al. This is an open access article distributed under the Creative Commons Attribution License, which permits unrestricted use, distribution, and reproduction in any medium, provided the original work is properly cited.

\begin{abstract}
The interactions in poly(oxyethylene) (E) - poly(oxybutylene) (B) of EB or EBE type block copolymers-sodium dodoecyl sulfate (SDS) or dodecyltrimethylammonium bromide (DTAB) and/or t-octylphenoxy polyethoxyethanol, (TX-100) have been monitored as a function of surfactant concentration and temperature. The addition of ionic surfactants to copolymer micellar solutions in general induced not only shape transition from spherical to prolate ellipsoids at $30^{\circ} \mathrm{C}$ in the copolymer micelles but also destabilize them and even suppress the micelle formation at high surfactant loading. DTAB destabilizes the copolymer micelles more than SDS. TX-100, being nonionic, however, forms stable mixed micelles. The block copolymer-surfactant complexes are hydrophilic in nature and are characterized by high turbid and cloud points. Triblock copolymer micelles got easily destabilized than the diblock copolymer ones, indicating the importance of the interaction between the hydrophilic E chains and surfactants. The effects of destabilization of the copolymer micelles are more dominating than the micellar growth at elevated temperatures, which is otherwise predominant in case of copolymer micelles alone.
\end{abstract}

\section{Introduction}

Amphiphilic block copolymers of type $\mathrm{E}_{n} \mathrm{~B}_{m}$ or $\mathrm{E}_{n} \mathrm{~B}_{m} \mathrm{E}_{n}$ ( $\mathrm{E}=$ oxyethylene and $\mathrm{B}=$ oxybutylene, and $m$ and $n$ indicate the number of units) have several advantages over EPE ( $\mathrm{P}=$ oxypropylene $)$ copolymers. For example, B block is more hydrophobic than P block and EB or EBE copolymers are fairly homogeneous in composition [1]. The surfactantlike properties including gelation behavior of several of laboratory synthesized or commercial $\mathrm{E}_{n} \mathrm{~B}_{n}$ and $\mathrm{E}_{n} \mathrm{~B}_{m} \mathrm{E}_{n}$ copolymers in aqueous media have been the subject of many scientific investigations [2-21]. In colloidal engineeringbased applications such as detergency, dispersion, stabilization, foaming, emulsification, lubrication, control release of drugs, the block copolymers and low molar mass surfac- tants are often used in combination with each other. Therefore, the studies on copolymer-surfactant mixture solutions are essential to find out best suitable conditions for achieving their optimum performance $[22,23]$. A literature survey reveals that much of the research work on amphiphilic copolymer-surfactant mixed systems in water focused on EPE copolymers-sodium dodecyl sulfate (SDS), sodium dodecylbenzene sulfonate (SDBS), cetyltrimethylammonium chloride (CTAC) or bromide (CTAB)) or polyether-based nonionic surfactants, and so forth [23]. Detailed investigations dealing with the establishment of binding isotherms, measurement of critical micelle concentrations, determination of size and aggregation number in mixed systems have indicated that the surfactant molecules interact with the hydrophobic as well as hydrophilic parts of the copolymers 
and induce interesting and dramatic changes in association characteristics depending upon the molecular characteristics of copolymers, namely, length of $\mathrm{E}$ or $\mathrm{P}$ blocks, $\mathrm{P} / \mathrm{E}$ ratio and also on the type of hydrophobic block and concentration of the surfactants, and so forth. Whether the added surfactants would form simply mixed micelles, induce the copolymer micellization or form copolymer-surfactant complexes, break the complexes and inhibit the copolymer micellar growth, were highly dependent on the surfactant concentrations and also on the overall hydrophilicity or hydrophobicity of the copolymers. The mixed micelle formation in EPE copolymer-surfactants systems were also reported [24-28]. The interaction parameter was calculated using regular solution theory. It has been emphasized that the mixing behavior deviated from ideality and the systems exhibited synergistic interactions.

Recently, Kelarakis et al. [29, 30] had monitored the interactions of SDS with series of poly (oxyethylene)poly (oxybutylene) diblock and poly(oxyethylene)-poly (oxybutylene)-poly (oxyethylene) triblock copolymers $\left(\mathrm{E}_{18} \mathrm{~B}_{10}, \mathrm{~B}_{20} \mathrm{E}_{610}, \mathrm{~B}_{12} \mathrm{E}_{277} \mathrm{~B}_{12}\right.$, and $\left.\mathrm{E}_{40} \mathrm{~B}_{10} \mathrm{E}_{40}\right)$ using DLS, electrical conductance, volumetric, ultrasonic velocity, and small angle X-ray scattering (SAXS) measurements. Unlike in EPE copolymer-surfactant systems, the addition of SDS to $\mathrm{B}_{18} \mathrm{E}_{10}$ (which is a predominantly hydrophobic copolymer) led to the formation of large vesicles with positive deviations from the ideal mixing. It was also emphasized that the length of the hydrophilic block of the copolymer plays an important role not only in the interactions but also in the final size and shape of the particles formed in mixed systems. A clear picture and understanding on which way the added surfactants affects the self-association and phase behavior of EB or EBE copolymers is yet to emerge. Therefore, our present study reports the systematic measurements on the dilute aqueous solution phase characteristics, small angle neutron scattering (SANS), and dilute solution viscosity for mixture solutions of a diblock $\mathrm{E}_{18} \mathrm{~B}_{9}$ or triblock $\mathrm{E}_{13} \mathrm{~B}_{10} \mathrm{E}_{13}$ copolymers SDS, DTAB, a nonionic surfactant, t-octylphenoxy polyethoxyethanol, and TX-100 in water at different temperatures as a function of surfactant concentration. The results are hoped to shed some light on how the two opposing effects of micellar destabilization (by surfactants) and micellar growth (by temperature) get balanced or predominate over each other in such systems.

\section{Experimental Section}

2.1. Materials. The block copolymers were obtained as gift samples from The Dow Chemical Company, Freeport, Tex, USA and were used as received. The diblock copolymer, $\mathrm{BM}-45$, has a structure of type, $\mathrm{MeO}-(\mathrm{EO})_{18}-(\mathrm{BO})_{9}-\mathrm{OH}$ while the triblock copolymer, $\mathrm{B}-40$, has a structure, $\mathrm{HO}-$ $(\mathrm{EO})_{13}-(\mathrm{BO})_{10}-(\mathrm{EO})_{13}-\mathrm{OH}$. EO and $\mathrm{BO}$ in the structures represent oxyethylene and oxybutylene units, and $\mathrm{MeO}$ denotes a methoxy group. The di- and triblock copolymers have been denoted as B-1 $\left(\mathrm{E}_{18} \mathrm{~B}_{9}\right)$ and $\mathrm{B}-2\left(\mathrm{E}_{13} \mathrm{~B}_{10} \mathrm{E}_{13}\right)$. SDS was of Fluka made with purity $>98 \%$ on mass basis. DTAB and TX-100 were Aldrich products with purities of 99\% and 98\%. These samples were used as received without any purification. The critical micelle concentration (CMC) values as determined from surface tension isotherms at $30^{\circ} \mathrm{C}$ for the surfactants are $0.23,0.49$, and $0.021 \mathrm{~g} \cdot \mathrm{dl}^{-1}$ for SDS, DTAB, and TX-100 respectively.

2.2. Methods. The solutions of copolymers were prepared by dissolving the known amount either in triple distilled water or in a given surfactant solution and allowed to be swirled on a magnetic stirrer till homogenous, and thorough mixing is achieved. A stirring period of 60-90 minutes was found to be sufficient. The solutions were always stored in stoppered glass vials. The solutions of the individual surfactants were however, prepared by simple dissolution of required amounts with a care to minimize the foam formation. The solutions were allowed to stand for few hours till the overhead foam (if any) is fully settled.

2.3. Phase Diagrams. The dilute aqueous solution phase characteristics for each of the solutions were monitored by visual observation of typical changes in the appearance of solution through warming and cooling cycle. The average value of temperature for the two sessions was finally noted to identify the turbid $\left(T_{p}\right)$ and cloud points $\left(C_{p}\right)$. The uncertainty in these points is $\pm 0.5^{\circ} \mathrm{C}$.

2.4. Small Angle Neutron Scattering. The SANS experiments were carried out on B-1 or B-2 solutions and also on copolymer-surfactant mixture solutions in $\mathrm{D}_{2} \mathrm{O}$ using an indigenously built SANS spectrometer at the DHRUVA Reactor, (Trombay, India). The $\mathrm{D}_{2} \mathrm{O}$ (with at least 99.5 atom\% purity) was obtained from heavy water division of BARC, Mumbai, India. The use of $\mathrm{D}_{2} \mathrm{O}$ instead of $\mathrm{H}_{2} \mathrm{O}$ for preparing the solutions provides a very good contrast between the associates of solute and the solvent in SANS experiment. The solutions were held in $0.5 \mathrm{~cm}$ path length UV-grade quartz sample holders with tight and fitting teflon stoppers sealed with parafilm. The sample to detector distance was $1.8 \mathrm{~m}$ for all runs. The spectrometer makes use of a $\mathrm{BeO}$-filtered beam and has a resolution $(\Delta \mathbf{Q} / \mathbf{Q})$ of about $30 \%$ at $\mathbf{Q}=0.05 \AA^{-1}$. The angular distribution of the scattered neutron is recorded using one-dimensional position-sensitive detector. The accessible wave transfer $\mathbf{Q}(=4 \pi \sin 0.5 \theta / \lambda$, where $\lambda$ is the wave length of the incident neutrons and $\theta$ is the scattering angle) range of this instrument is between 0.02 and $0.3 \AA^{-1}$. The mean neutron wavelength was $\lambda=5.2 \AA$.

The measured scattering intensities of neutrons were corrected for the background, empty cell scattering, and sample transmission. The intensities then were normalized to absolute cross-section units. Thus, plots of $\mathbf{d} \Sigma / \mathbf{d} \Omega$ versus $\mathbf{Q}$ were obtained. The uncertainty in the measured scattering intensities is estimated to be $10 \%$. The experimental points are fitted using a nonlinear least squares method.

2.5. Viscosity. The flow times of individual copolymer aqueous solutions as well as mixtures of B-1 and B-2 surfactants were obtained by using Ubbelohde suspended level viscometers. Two viscometers were used to obtain flow times in the range of $130-360 \mathrm{~s}$, thus avoiding any kinetic corrections. Three consecutive flow times agreeing 


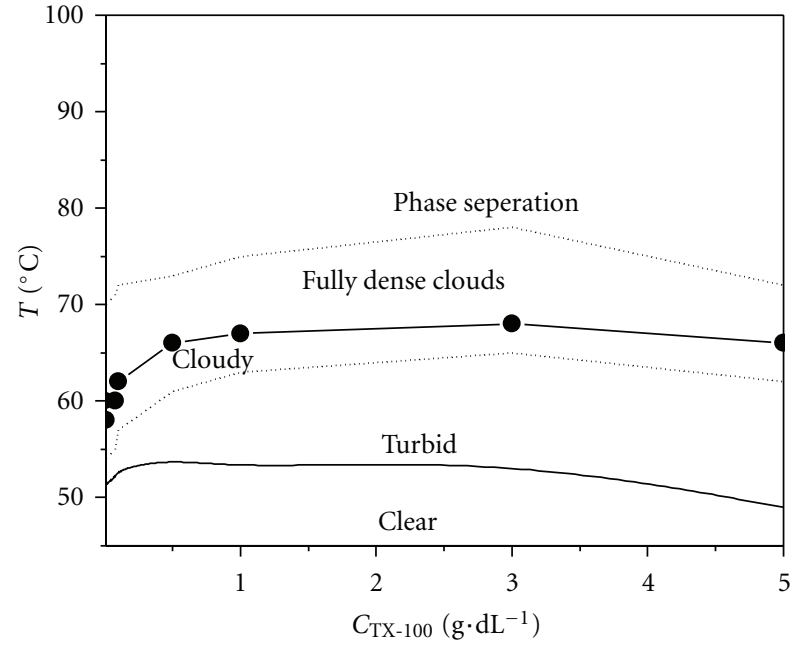

(a)

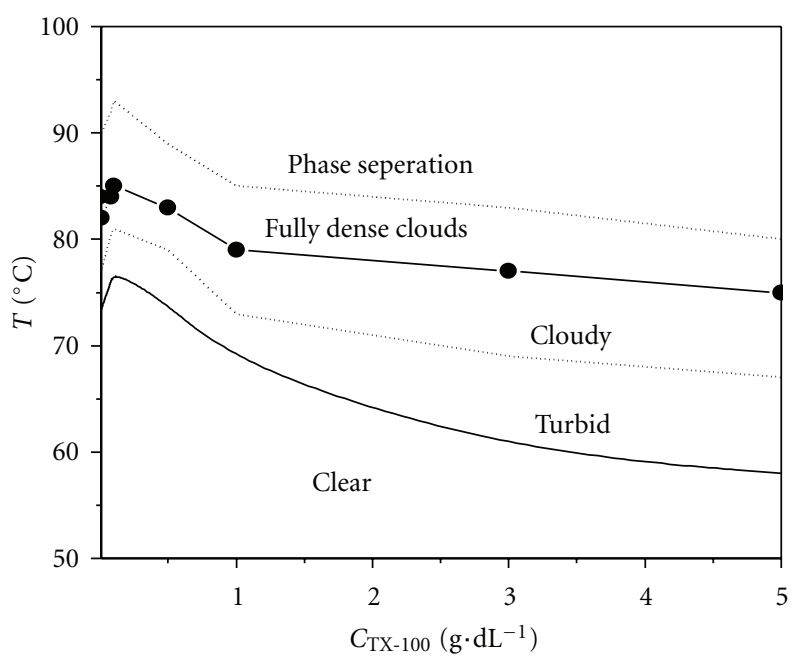

(b)

FIGURE 1: Dilute aqueous solution phase diagram for block copolymers-TX-100 mixtures: (a) B-1-TX-100 and (b) B-2-TX-100.

within $\pm 0.02 \mathrm{~s}$ were recorded, and the mean flow time was considered. Shear corrections were not taken into consideration, because obtained intrinsic viscosities were always less than $3 \mathrm{dl} \mathrm{g}^{-1}$. The flow volume was greater than $5 \mathrm{~mL}$, making drainage corrections unimportant. The viscometers during the measurements were suspended in thermostatic water baths maintained at constant temperature accurate to $\pm 0.01^{\circ} \mathrm{C}$.

\section{Results and Discussion}

3.1. Dilute Aqueous Solution Phase Diagrams. The features for aqueous solutions of B-1 and B-2 copolymers have been discussed previously $[31,32]$. The clear copolymer solutions (at room temperature) turned turbid before dense cloudiness sets in at higher temperatures. Therefore, typically, each solution possess a turbidity point $\left(T_{p}\right)$ and a cloud point $(C p)$. Diblock copolymer, has lower $T_{p}$ and $C_{p}$ values as compared to triblock copolymer and the temperature range over which the turbidity persisted in the solutions has also been found to be more for B-2 than B-1 copolymer. These trends are directly attributed to the fact that the triblock $\mathrm{E}_{13} \mathrm{~B}_{10} \mathrm{E}_{13}$ has longer hydrophilic $\mathrm{E}$ blocks than the diblock $\mathrm{E}_{18} \mathrm{~B}_{9}$. Therefore, the turbidity set in the solutions is due to the increased immiscibility of hydrophobic oxybutylene moiety at elevated temperatures. Similarly, our previous detailed SANS studies[31] on aqueous solutions of these copolymers revealed that they form spherical micelles consisting of an hydrophobic inner core surrounded by outer hydrophilic corona. The size and association number in the micelles systematically increased with the increase in temperature, and, in fact, the spherical micelles of B-2 copolymer underwent a shape transformation to highly asymmetrical ellipsoids at temperatures close to $T_{p}$. It was noticed that the appearance of turbidity in solutions coincided and was related to the growth of the micelles into large structures.
The dilute aqueous solution phase diagrams for a fixed $2 \mathrm{wt} \%(\mathrm{w} / \mathrm{v})$ aqueous solutions of B-1 or B-2 in presence of varying amounts of each of the surfactants; that is, SDS, DTAB, or TX-100 was constructed. The common features noted from the diagrams are (i) initial clear solutions turn turbid to cloudy, (ii) further increase in temperature resulted into formation of fully dense clouds, and (iii) result in phase separation at high temperatures. A typical phase diagram for block copolymers-TX-100 mixtures is shown in Figure 1. The phase diagrams for other mixtures are given in Figure S1 of Supplementary Material, which is available online at doi: $10.1155 / 2011 / 570149$. The summary of the turbid and cloud pints as extracted from these diagrams is collected in Table 1. A perusal of the data from Table 1 reveals that (i) the copolymers-SDS, -DTAB mixture solutions have higher $C_{p}$ values as compared to the copolymer solutions alone in water, (ii) the successive addition of surfactants as additives increased the $C_{p}$ values and the same appeared to be greater than $100^{\circ} \mathrm{C}$ at very high SDS and DTAB loading (iii) the addition of nonionic TX-100 to the copolymer solutions on the contrary did not produce such large effects and the cloud points are well below $100^{\circ} \mathrm{C}$, and (iv) the copolymerTX-100 mixture solutions got phase separated at elevated temperatures.

In view of these observed sharp contrasting clouding behavior between the copolymers-ionic surfactant mixtures on one hand and copolymers-nonionic surfactant mixtures on the other, we thought it interesting to undertake detailed SANS measurements in mixture solutions under solution conditions of either varying surfactant concentrations at a given temperature and or either varying temperatures (from room temperature to high temperatures close to the $T_{p}$ ) for a fixed surfactant concentration so that we hope to get an insight in to the changes in the geometrical features of copolymer micelles under two competitive effects of micelle destabilization and micellar growth. 


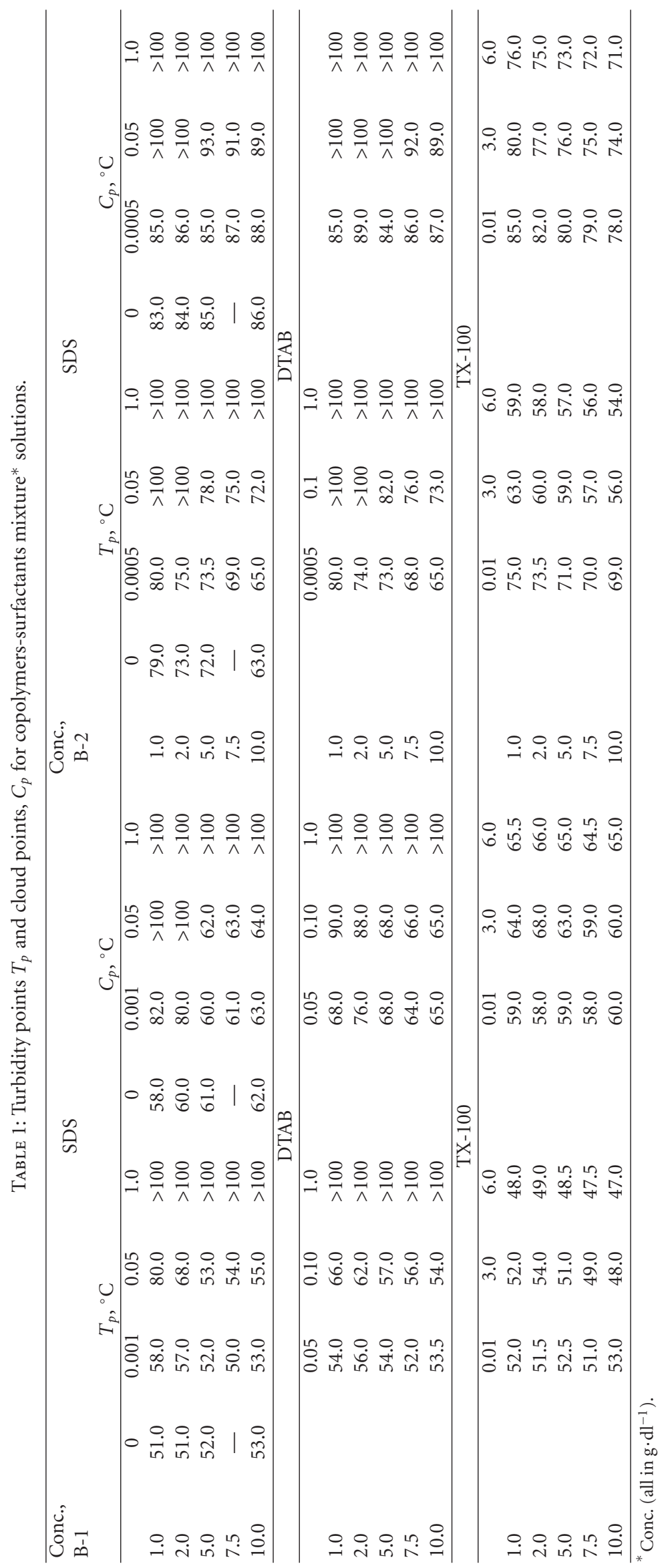




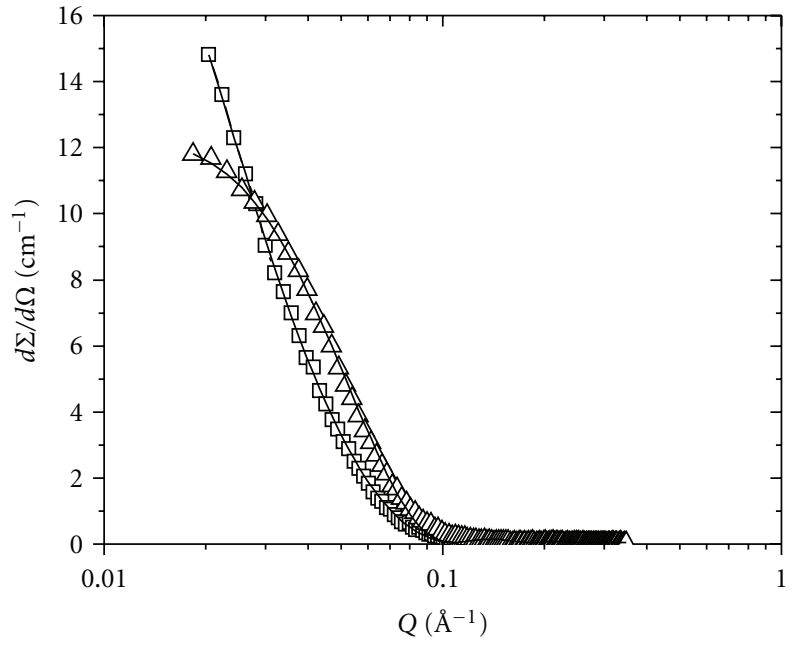

(a)

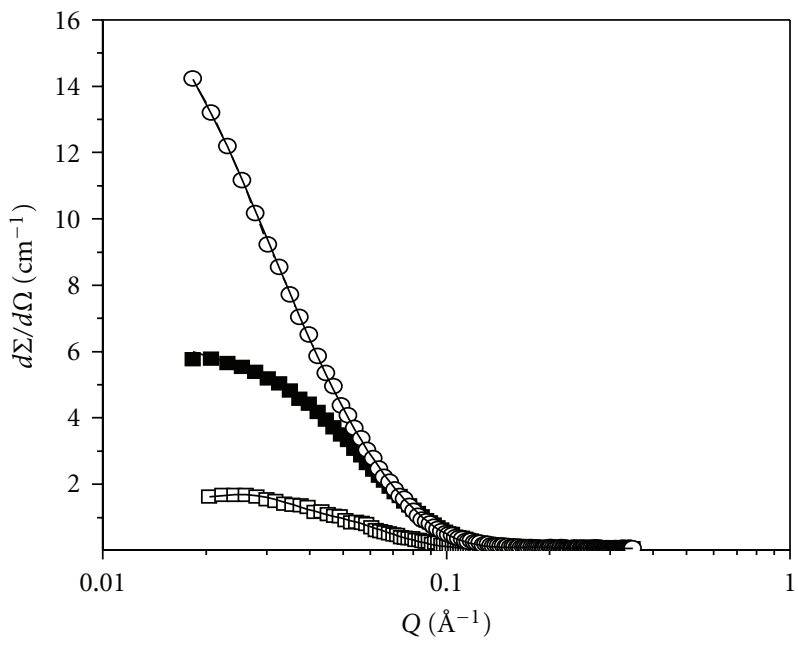

(b)

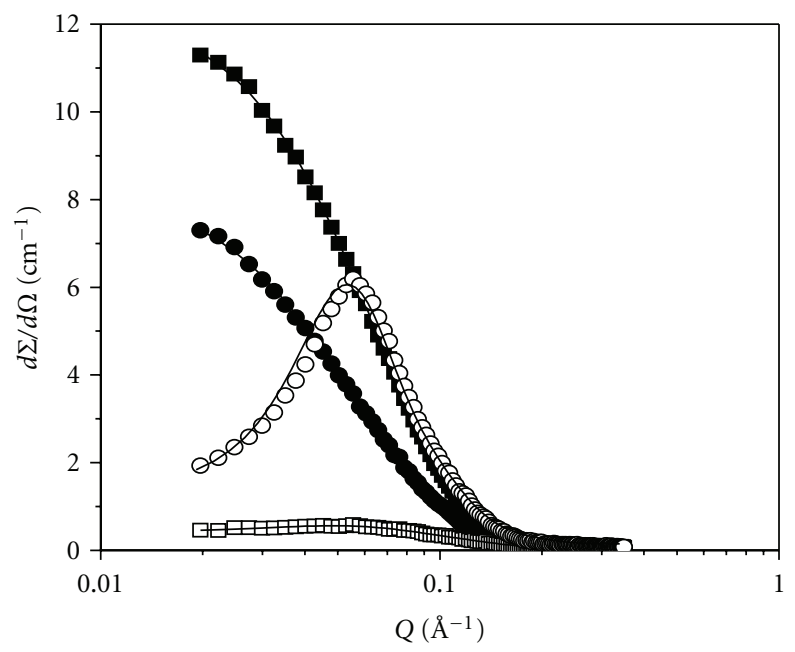

(c)

FIGURE 2: SANS distribution for copolymer or surfactant solution in $\mathrm{D}_{2} \mathrm{O}$ at different temperatures (in $\left.{ }^{\circ} \mathrm{C}\right)(\mathrm{a}) 2 \%(\mathrm{w} / \mathrm{v}) \mathrm{B}-1$ : $(\triangle) 30^{\circ} \mathrm{C}$, ( $\square$ ) $50^{\circ} \mathrm{C}$; (b) $2 \%(w / v) ~ B-1:(\square)\left(30^{\circ} \mathrm{C}\right),(\square) 50^{\circ} \mathrm{C},(\bigcirc) 70^{\circ} \mathrm{C}$; (c) $(\bigcirc) 2.4 \%$ SDS at $30^{\circ} \mathrm{C},(\square) 1 \%$ DTAB $30^{\circ} \mathrm{C},(\bullet) 3 \%$ and $(\mathbf{\square}) 6 \%$ TX-100 at $30^{\circ} \mathrm{C}$. Curves represent the model fitted values.

3.2. Small Angle Neutron Scattering (SANS). SANS measurements were carried out first on the solutions of the individual copolymers or surfactants in $\mathrm{D}_{2} \mathrm{O}$ at different temperatures and the spectra are shown in Figure 2. The concentrations chosen are far excess than the CMC of respective pure components. The analysis of the spectra took into the consideration of the differential scattering crosssection per unit volume as a function of scattering vector $Q$ and is expressed as [33-37]

$$
\frac{\mathbf{d} \Sigma}{\mathbf{d} \Omega}=\mathbf{n}_{m} \mathbf{V}_{m}^{2}\left(\boldsymbol{\rho}_{m}-\boldsymbol{\rho}_{s}\right)^{2} \mathbf{P}(\mathbf{Q}) \mathbf{S}(\mathbf{Q})+\mathbf{B} .
$$

The above expression can be simplified for noninteracting micelles. (i.e., for dilute solutions, the inter particle structure factor $\mathbf{S}(\mathbf{Q})$ may be equated to $\sim 1)$ as

$$
\frac{\mathbf{d} \Sigma}{\mathbf{d} \Omega}=\mathbf{n}_{m} \mathbf{V}_{m}^{2}\left(\boldsymbol{\rho}_{m}-\boldsymbol{\rho}_{s}\right)^{2} \mathbf{P}(\mathbf{Q})+\mathbf{B},
$$

where $n_{m}$ denotes the number density of micelles, $V_{m}$ is the micellar volume, and $\rho_{m}$ and $\rho_{s}$ are scattering length densities of the micelles and solvent, respectively. $\mathbf{P}(\mathbf{Q})$ is the single particle (intraparticle) structure factor, and $\mathbf{S}(\mathbf{Q})$ is the interparticle structure factor. $\mathbf{B}$ is a constant term that represents the incoherent scattering from the background, which is mainly due to hydrogen in the sample. The $\mathbf{P}(\mathbf{Q})$ for spherical micellar core can be written as

$$
\mathbf{P}(\mathbf{Q})=\left[\frac{3}{\left(\mathbf{Q} R_{c}\right)^{3}}\left(\sin \left(\mathbf{Q} R_{c}\right)-\mathbf{Q} R_{c} \cos \left(\mathbf{Q} R_{c}\right)\right)\right]^{2},
$$

where $R_{c}$ is the hydrophobic core radius which is attributed to the size of the micellar core. The interparticle structure 
factor $\mathbf{S}(\mathbf{Q})$ depends on the spatial distribution of micelles and is given by [38]

$$
\mathbf{S}(\mathbf{Q})=1+4 \pi n \int(g(\mathbf{r})-1) \frac{\sin (\mathbf{Q} \mathbf{r})}{\mathbf{Q r}} \mathbf{r}^{2} \mathbf{d r}
$$

where $g(\mathbf{r})$ is the radial distribution function describing the arrangement of the micelles.Percus and Yevick approximation [39] for describing a direct correlation between two scattering objects, defines the analytical form of structure factor as [40-42]

$$
\mathbf{S}(\mathbf{Q})=\frac{1}{1+24 \phi G\left(2 \mathbf{Q} R_{\mathrm{hs}}, \phi\right) /\left(2 \mathbf{Q} R_{\mathrm{hs}}\right)},
$$

where $R_{\mathrm{hs}}$, the hard sphere micellar radius, consisting of both poly (oxybutylene) and poly (oxyethylene) and is the physical size of the micelle. $\phi$ is the hard sphere volume fraction of the micelles in the solution. $G$ is a function of $\mathbf{x}=2 \mathbf{Q} R_{\mathrm{hs}}$ and $\phi$.

The $\phi$ value can mathematically be made equivalent to

$$
\left(C_{m} 4 \pi R_{\mathrm{hs}}^{3} N_{A}\right) / 3 N 1000
$$

where $C_{m}$ is the concentration of copolymer molecules in associated (micellized) form and has an unit in terms of mol dm ${ }^{-3}$.

The micelles of copolymers or surfactants in water consist of hydrophobic core surrounded by hydrophilic corona. The scattering length densities of polyoxybutylene $\left(0.212 \times 10^{10} \mathrm{~cm}^{-2}\right), \quad$ SDS $\left(-0.392 \times 10^{10} \mathrm{~cm}^{-2}\right)$, DTAB $\left(0.392 \times 10^{10} \mathrm{~cm}^{-2}\right)$, TX-100 $\left(0.388 \times 10^{10} \mathrm{~cm}^{-2}\right)$, and $\mathrm{D}_{2} \mathrm{O}\left(6.38 \times 10^{10} \mathrm{~cm}^{-2}\right)$ were used in the calculations. There is a very good contrast between the hydrophobic core and the solvent. However, because of large amount of $\mathrm{D}_{2} \mathrm{O}$ (water of hydration) present in the outer polyoxyethylene corona, the scattering contrast between the hydrated corona and the solvent shall expected to be poor. In view of above, we assume that $\mathbf{P}(\mathbf{Q})$ depends only on the hydrophobic core radius. Thus, in fitting experimental neutron scattering data from solutions to (1), three unknown parameters, core radius, $R_{c}$, hard sphere interaction radius, $R_{\mathrm{hs}}$ and volume fraction of the micelles, $\phi$ have been considered as fitting parameters in the analysis. The association number, $N$, then can be obtained from the knowledge of the core size

$$
N=\frac{4 \pi\left(R_{C}\right)^{3}}{3 n V_{\mathrm{BO}}},
$$

where $n$ is the number of oxybutylene units in the hydrophobic block, $R_{c}$ is the radius of the anhydrous core and $V_{\mathrm{BO}}$ is the volume of one oxybutylene unit $\left(116.5 \% 10^{-24} \mathrm{~cm}^{3}\right)$. From the estimated values of $N$, the number density of micelles, $\zeta$ that is the number of copolymer micelles per unit volume is calculated by following relation:

$$
\frac{\zeta}{\mathrm{cm}^{-3}}=\frac{C \times N_{A} \times 10^{-3}}{N}
$$

where $C=$ concentration in $\mathrm{moldm}{ }^{-3}, N_{A}=$ Avogadro's number.
B-1 or B-2 Spherical Micelles in Water. Various micellar parameters such as core radius, $R_{c}$, and hard sphere radius, $R_{\mathrm{hs}}$, volume fraction, $\phi$, and intermicellar distance, $\zeta$, as obtained from the above treatment of SANS data at $30^{\circ} \mathrm{C}$ are listed in Table 2. SANS intensities for the diblock copolymer solutions were greater than that of the triblock copolymer solutions, and accordingly, the association number and number density of the diblock copolymer were higher than the for triblock copolymer micelles. The observed smaller micellar dimensions for a triblock copolymer can be explained by the fact that core part of its micelle has two block junctions at the core/fringe interface as compared to only one such constraint in the micelle of a diblock copolymer. This effectively restricts the freedom of hydrophobic chain within the core of the micelle.

The analysis of the SANS curves at high temperatures could only be done by assuming ellipsoidal $\mathbf{P}(\mathbf{Q})$ factor, while the $\mathbf{S}(\mathbf{Q})$ factor at high temperatures has been set equal to unity as correlation peaks were absent. The various parameters of copolymer micelles at different temperatures are also listed in Table 2. It can be seen that the increase in temperature induced the shape transformation in copolymer micelles. The increase in temperature $\left(50^{\circ} \mathrm{C}\right.$ to $70^{\circ} \mathrm{C}$ for B2) resulted in a drastic increase of the major axis " $b$ ". The distortion of the spherical shape at elevated temperatures was also followed by an increase in association number, and these changes are mainly attributable to the expulsion of water molecules from the core as well as the hydrated corona of the micelles. Under these conditions, more copolymer molecules can be accommodated in a micelle and hence $N$ of the micelles increases.

Surfactant Micelles in Water. The SANS distributions and their detailed analysis for anionic sodium dodecyl sulfate, cationic tetradecyltrimethylammonium bromide DTAB, and nonionic TX-100 in water have been reported elsewhere [43]. The surfactant micelles were typically prolate ellipsoidal in shape with their hydrocarbon tails occupying the interior hydrophobic core surrounded by the head groups. The micellar parameters for these three surfactants, as extracted from the SANS analysis are summarized in Table 3.

Copolymer-Surfactant Mixtures. SANS measurements on the solutions of $2 \%$ B- $1+$ SDS $(0.001,0.05$ and $1 \%),+$ DTAB $(0.05,0.1$ and $1 \%)$, and + TX-100 $(6 \%)$ mixtures at $30^{\circ} \mathrm{C}$ as well as at elevated temperatures were and the corresponding SANS curves are shown in parts (a)-(c) and (d)-(f) of Figure S2 of Supplementary Material. In the analysis of mixture spectra, the scattering length, SL and volume of hydrophobic parts, $V$ for the mixture solutions as calculated from the relations

$$
\begin{gathered}
\mathrm{SL}_{\text {mix }}=\mathrm{SL}_{S}-\left(\frac{C_{\mathrm{Cop}}}{C_{\mathrm{Cop}}}-\mathrm{C}_{S}\right) \mathrm{SL}_{\mathrm{Cop}} \\
V_{\text {mix }}=V_{S}-\left(\frac{C_{\mathrm{Cop}}}{C_{\mathrm{Cop}}}-C_{S}\right) V_{\mathrm{Cop}}
\end{gathered}
$$

were fed into the analytical program. The subscripts Cop and $S$ indicate copolymer and surfactants, respectively. 
TABLE 2: Micellar parameters for $2 \%(\mathrm{w} / \mathrm{v})$ copolymer solutions in $\mathrm{D}_{2} \mathrm{O}$ at different temperatures.

\begin{tabular}{|c|c|c|c|c|c|c|c|c|c|}
\hline$T /{ }^{\circ} \mathrm{C}$ & $R_{c} \AA$ & $\begin{array}{r}R_{\mathrm{hs}} \AA \\
\mathrm{B}-1\end{array}$ & $\phi$ & $N$ & $T /{ }^{\circ} \mathrm{C}$ & $R_{c} \AA$ & $\begin{array}{c}R_{\mathrm{hs}} \AA \\
\mathrm{B}-2 \\
\end{array}$ & $\phi$ & $N$ \\
\hline \multicolumn{6}{|c|}{ Hard Sphere } & \multicolumn{4}{|c|}{ Hard Sphere } \\
\hline \multirow[t]{2}{*}{30} & 43 & 98 & 0.028 & 318 & 30 & 35 & 70 & 0.024 & 154 \\
\hline & $\mathrm{a} \AA$ & $\mathrm{b} \AA$ & $\mathrm{a} / \mathrm{b}$ & $N$ & & a $\AA$ & $\mathrm{b} \AA$ & $\mathrm{a} / \mathrm{b}$ & $N$ \\
\hline \multicolumn{6}{|c|}{ Prolate ellipsoidal } & \multicolumn{4}{|c|}{ Prolate ellipsoidal } \\
\hline \multirow[t]{2}{*}{50} & 136 & 37 & 3.7 & & 50 & 50 & 28 & 1.8 & 136 \\
\hline & & & & & 70 & 117 & 29 & 4.0 & 356 \\
\hline
\end{tabular}

TABLE 3: Micellar parameters for prolate ellipsoids of surfactant solutions in $\mathrm{D}_{2} \mathrm{O}$ at $30^{\circ} \mathrm{C}$.

\begin{tabular}{|c|c|c|c|c|c|c|c|c|c|}
\hline $\begin{array}{l}\text { Conc., } \\
\mathrm{g} \cdot \mathrm{dl}^{-1}\end{array}$ & $\mathrm{~b} \AA \AA$ & a $\AA$ & $\mathrm{b} / \mathrm{a}$ & $N$ & $\begin{array}{l}\text { Conc., } \\
\mathrm{g} \cdot \mathrm{dl}^{-1}\end{array}$ & $\mathrm{~b} \AA$ & a $\AA$ & $\mathrm{b} / \mathrm{a}$ & $N$ \\
\hline & & SDS & & & & & DTAB & & \\
\hline \multirow[t]{2}{*}{2.4} & 22 & 13 & 1.7 & 73 & 1 & 22 & 11 & 2.0 & 52 \\
\hline & & TX-100 & & & & & & & \\
\hline 3 & 12 & 38 & 3.2 & 190 & & & & & \\
\hline 6 & 12 & 39 & 3.3 & 198 & & & & & \\
\hline
\end{tabular}

By this way, we could calculate the association number of surfactants, $N_{S}$, in mixture solutions. The scattering lengths corresponding to the hydrophobic part of the individual copolymers or surfactants are B-1 $\left(2.223 \times 10^{-12}\right)$, B-2 $\left(2.474 \times 10^{-12}\right)$, SDS $\left(-1.374 \times 10^{-12}\right), \quad$ DTAB $\left(1.772 \times 10^{-12}\right)$, and TX-100 $\left(1.453 \times 10^{-12}\right) \mathrm{cm}$, respectively. Similarly, the volume (in $\AA^{3}$ ) of hydrophobic part of the respective copolymers and surfactants are B-1 (1047), B-2 (1162), SDS (350.2), DTAB (452.2), and TX-100 (374.6). The association number of the copolymer $N_{\text {Cop }}$ was then calculated by the relation

$$
N_{\text {Cop }}=\left(C_{\text {Cop }} / C_{\text {Cop }}-C_{S}\right) N_{S}
$$

B-1-SDS Mixtures. Our main aim is to monitor the effect of added SDS on the relative stability of B-1 micellar associates, and therefore, the SANS data were analyzed by a similar procedure used for B-1 solutions in $\mathrm{D}_{2} \mathrm{O}$. The various parameters as extracted from the analysis and formulations as described above are listed in Table 4. A perusal of the data shows that the addition of SDS unimers or micelles systematically decreased the $R_{c}$ and $R_{\mathrm{hs}}$ and also the association number of copolymer micelles. The mixture containing $1 \%$ SDS is highly interesting, because its solution remained clear even up to temperatures close to $100^{\circ} \mathrm{C}$. Since the mixed state is expected to have contribution from the micelles of both the components, it is quite likely that the contribution of the copolymer micelles to the aqueous solution phase characteristics would be bare minimum. In fact, our analysis revealed that there are 2 B-1 copolymer molecules per about 93 SDS molecules in this mixture, indicating that the micellization of B-1 is completely suppressed at high SDS concentrations. The decrease of size and suppression of B-1 micellization in mixture solutions need to be accounted. SDS molecules both in unassociated and associated form strongly interact with the hydrophobic and hydrophilic parts of B-1 unimeric molecules to form charged complexes. It is possible that several SDS unimers or micelles are associated with a single B-1 molecule, as we noticed $\sim 1: 45$ ratio in a copolymerSDS complex. The SDS-B-1 complex formation depletes the copolymer unimers and the extent of depletion increases with the increase in SDS concentration. This leads to the shift in the equilibrium, unimer $\leftrightarrow$ micelles progressively to the left, resulting into a decreased micellar dimensions. At high surfactant concentrations, the copolymer molecules are saturated with the negatively charged SDS molecules. The resultant repulsions among the negative head groups of copolymer-bound SDS molecules or micelles suppress the copolymer micelle formation all together. A direct evidence for the existence of such repulsions among copolymerSDS complexes comes from the fact that the $Q$ value corresponding to the maximum peak $\left(Q_{\max }\right)$ systematically shifted to the right of the scale with the increase in the SDS concentration indicating that the inter particle distance increases at high SDS concentrations. Kelarakis et al. [29, 30] have studied the same copolymer-SDS system by DLS and confocal microscope measurements at $25^{\circ} \mathrm{C}$ and noted that the addition of SDS (in the mole fraction range from 0.25 to 0.8 ) induced the formation of particles much larger than the micelles of copolymer and the super structures got decomposed at high SDS loading $\left(x_{\mathrm{SDS}}>0.8\right)$. The present work covers a mole fraction of SDS, $x_{\text {SDS }}(0.0028$ to 0.735 ), and the analysis of SANS data did not show the presence of any large structures, and on the contrary, SDS addition resulted in the destabilization of B-1 micelles usually observed with EPE copolymers-SDS systems[23]. As indicated by the authors, the spherical micelles in $1 \%$ $(\mathrm{w} / \mathrm{v})$ solution of $\mathrm{E}_{18} \mathrm{~B}_{10}$ in fact transformed to worm like micelles in the temperature range of $50^{\circ} \mathrm{C}$ to $60^{\circ} \mathrm{C}$ due to 
probable dehydration effects. Dehydration of corona part of the copolymer micelles can also be caused by the salt addition $[44,45]$.

B-1-DTAB. An examination of the micellar parameters namely semiminor axis, a, semimajor axis, b, fractional charge, $\alpha$, and association numbers of $N_{\mathrm{B}-1}$ and $N_{\mathrm{DTAB}}$ as listed in Table 4 shows that spherical micelles of B-1 copolymer undergo a shape transition from hard sphere to ellipsoids upon its interaction with DTAB unimers. The successive increase of DTAB mole fraction (from 0.1149 to 0.7219 ) decreased drastically the number of B-1 molecules in mixed micelles and in fact completely suppressed the B-1 micellization at high mole fraction. The $Q_{\max }$ value is initially shifted to a lower value followed by a gradual increase with the increase in DTAB mole fractions. This observation is in contrast to the trends noted in B-1-SDS mixtures. Therefore, the structure and nature of the associates in B-1-SDS and B1-DTAB mixtures need to be different. The $\left(\mathrm{CH}_{3}\right)_{3} \mathrm{~N}^{+}$-head group of DTAB molecules is more hydrophobic and bulky as compared to the $-\mathrm{SO}_{4}{ }^{-}$of SDS. Therefore, the arrangement of DTAB molecules or micelles within the B-1 molecular or associate structures would be such that the methyl groups of the head group are drawn towards the hydrophobic B units. Such twisting configuration not only facilitates more DTAB molecules but also induce the shape transition from hard spherical to open ellipsoidal structures as a result of steric as well as repulsive interactions. The repulsions among the charged complexes of B-1-DTAB would push away the individual mixed micelle, and thus causing a shift in the $Q_{\max }$ to lower values. At higher DTAB concentrations, however, the repulsions are so large and suppress the B-1 micelle formation, and the mixed micelles simply resemble DTAB pure micelles.

B-1-TX-100. The SANS distribution trace for single mixture of B-1-TX-100 (part c of Figure S2) is quite similar to the curve for TX-100 solutions in $\mathrm{D}_{2} \mathrm{O}$, and data was found to be best reproduced with a form factor $F(Q)$ of ellipsoidal core. The contribution from $S(Q)$ was considered to be unity (since no correlation peak was observed). The mixed micelles with a predominant contribution from TX-100 molecules were formed at the expense of spherical copolymer micelles.

B-2-Surfactants Mixtures. In order to study how the copolymer architecture affects the associate structures in the mixed state, we selected three mixtures with a fixed $2 \%(\mathrm{w} / \mathrm{v})$ concentration of $\mathrm{E}_{13} \mathrm{~B}_{10} \mathrm{E}_{13}$ triblock copolymer and maximum concentration of individual surfactants. The analysis of SANS data revealed that the shape of the associates is spherical (in B-2-SDS) and prolate ellipsoidal (in B-2DTAB and -TX-100). The perusal of the micellar parameters, as listed in Table 4, further revealed that the addition of the surfactants in high concentrations, irrespective of their nature, not only induce more dissociation of B-2 micelles as compared to B-1 micelles but also largely suppressed B2 micelle formation. The associates in the mixed state are predominantly dominated by surfactant micelles. B-1 and B2 have almost identical number of B units but differ both in the molecular architecture and number of E units. B-2 has longer $\mathrm{E}$ blocks at both ends, while B-1 has one terminal shorter E block. Therefore, it can inferred that the E block of the copolymers plays an important role in their interactions with the surfactants. The more the number of $\mathrm{E}$ units or longer its length, more will be the binding of the surfactants and hence more would be the destabilization or suppression of copolymer micelle formation.

Temperature Dependence. The SANS distributions at different temperatures could be fitted by considering the $\mathbf{P}(\mathbf{Q})$ and $\mathbf{S}(\mathbf{Q})$ or only $\mathbf{P}(\mathbf{Q})$, or $\mathbf{F}(\mathbf{Q})$ based on ellipsoidal dense core depending upon whether the curves are characterized by correlation peaks or not. The micellar parameters at different temperatures, as extracted from the analysis, are given in Table 4. A close scrutiny of the data reveals that the addition of surfactants facilitated the SANS measurements at high temperatures, as solutions in the mixed state were clear. As usual, the increase in the temperature induced the transformation of shape of the micelles (of both the copolymers) (see Table 2) from spherical to prolate ellipsoids with many fold increase in the association number. The addition of surfactants (in low concentration) decreased the association number of the mixed micelles indicating the predominance of contribution from copolymer-ionic surfactant interaction over the usual temperature effects. At high loading of ionic surfactants, the copolymer micelles are dissolved to their unimeric or multimeric forms. The case of copolymers-TX-100 systems presented a different scenario. Irrespective of whether the TX-100 is in its unimeric or micellar form, its addition at elevated temperatures resulted in the gradual decrease in the contribution of copolymer molecules in the mixed micelles. Even at very high TX100 loading, considerable number of copolymer molecules formed the part of the mixed micelles. Since both the copolymers as well as TX-100 surfactants are nonionic in nature, the copolymer-TX-100 complexes are more stable because of the absence of any repulsions, and this may be the reason for the formation of stable mixed micelles in this system.

3.3. Viscosity Measurements. The utility of dilute solution viscosity measurements on the copolymer aqueous solutions is interesting, as they enable the determination of intrinsic viscosities, $[\eta]$, an important parameter to adjudge the hydrophilic character. The representative profiles of reduced viscosities as a function of copolymer concentrations in water as well as for copolymers-SDS mixed systems at $30^{\circ} \mathrm{C}$ as well as at elevated temperatures are shown in parts (a) and (b) of Figure 3. The plots are linear and fitted well with the Huggins equation, $\eta_{\mathrm{sp}} / C=[\eta]\left\{1+k_{H}[\eta] C\right.$, where $k_{H}=$ Huggins constant. The intrinsic viscosities, $[\eta]$, of the copolymer-surfactant complex systems were obtained by extrapolation of reduced viscosities, $\eta_{\mathrm{sp}} / C$, to zero concentration. The summary of intrinsic viscosities and $k_{H}$ for the mixed systems is given in Table 5 . The $[\eta]$ values at $30^{\circ} \mathrm{C}$ systematically increased with (i) the increase in the concentration of any of the three surfactants and (ii) the increase in temperature. B-2-surfactants mixtures have been 


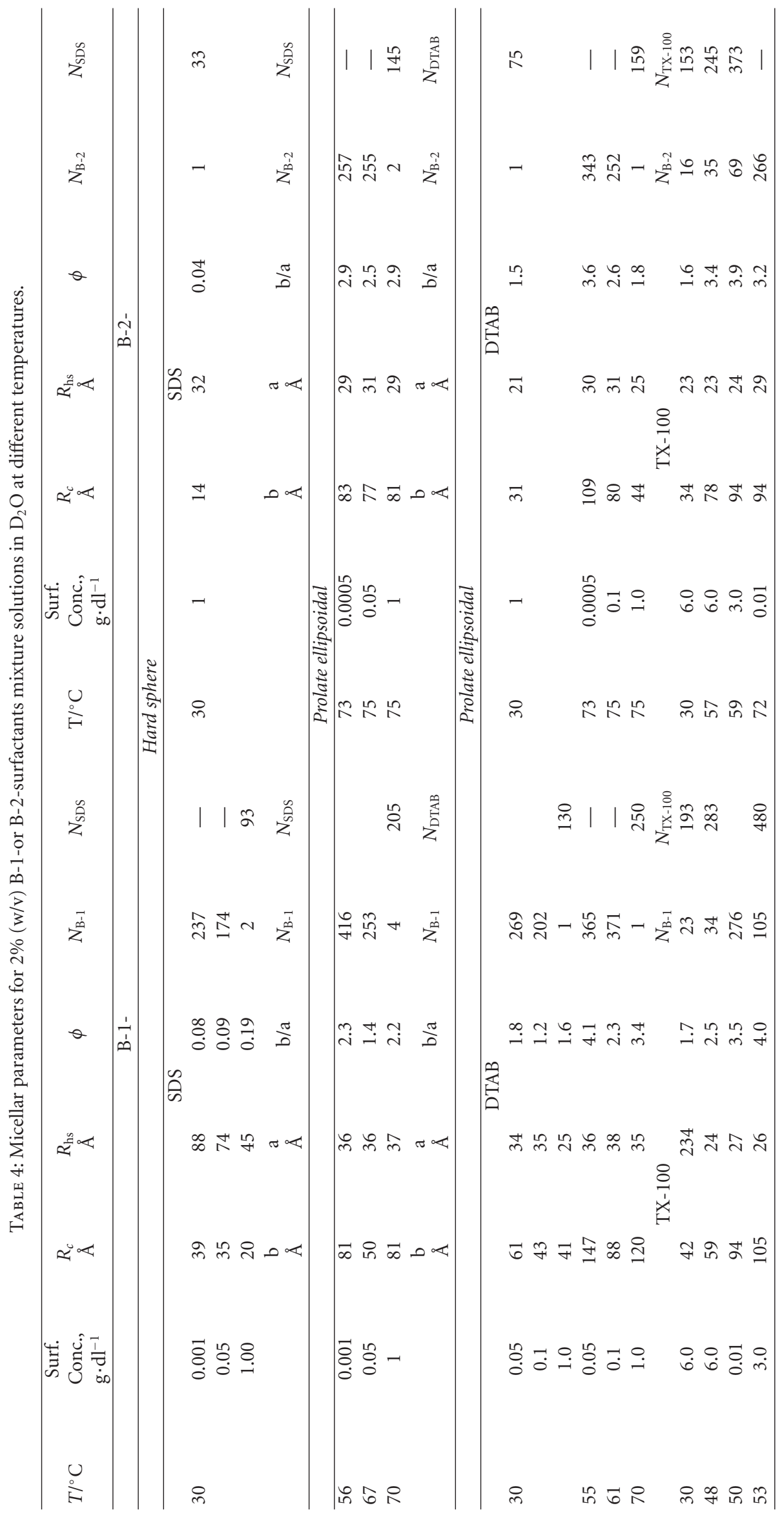




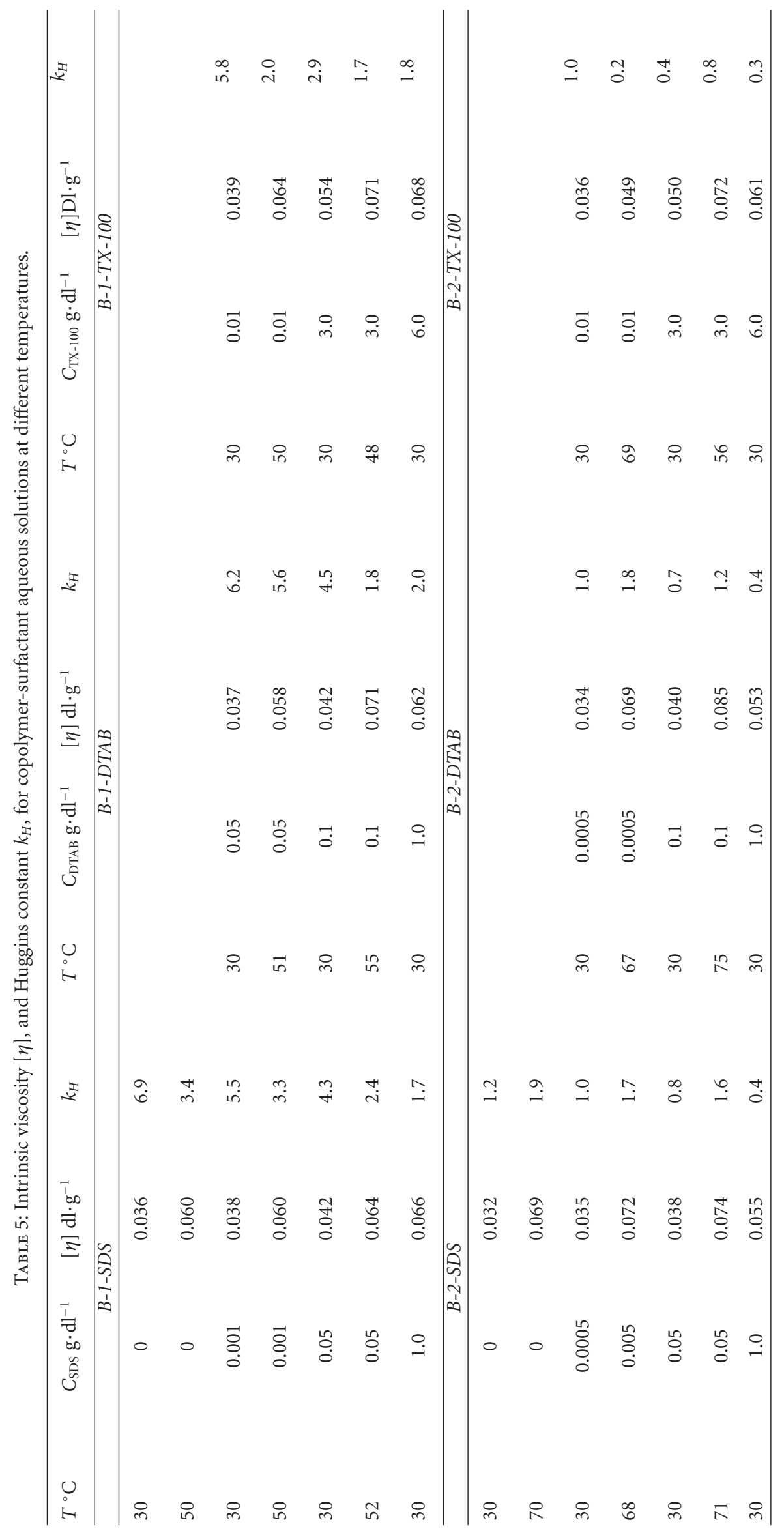




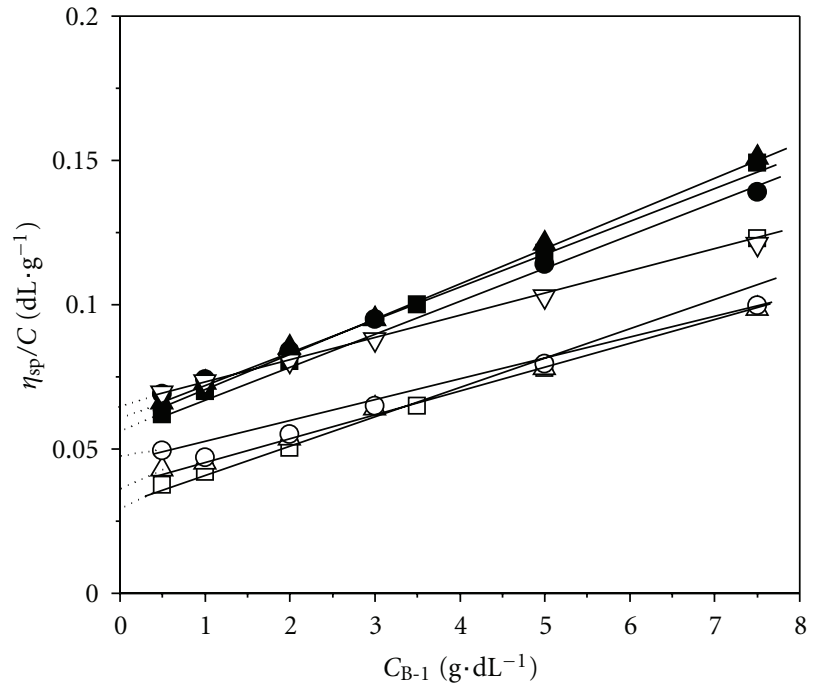

(a)

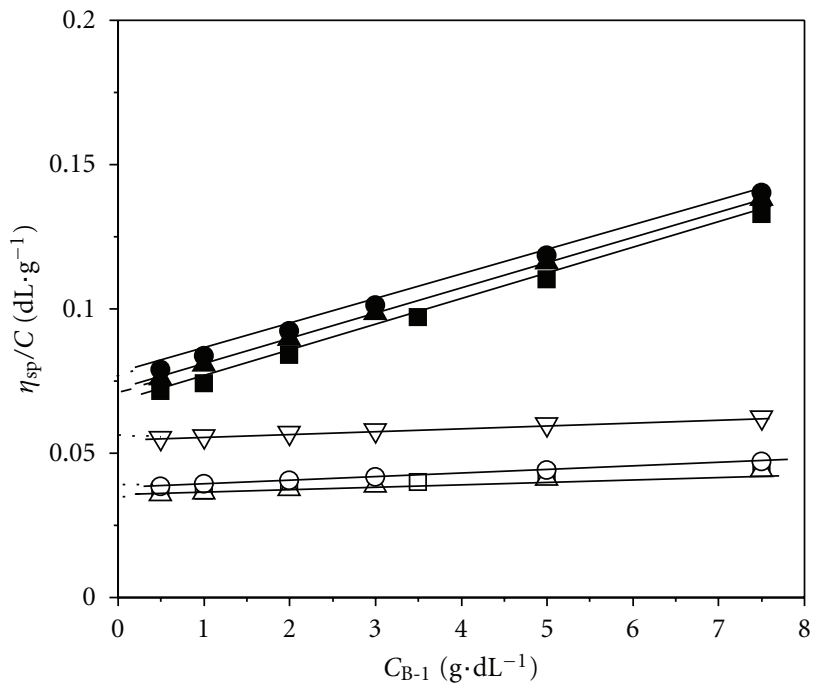

(b)

Figure 3: Reduced viscosity for B- $1+$ surfactant mixtures in aqueous solutions at different temperatures (in ${ }^{\circ} \mathrm{C}$ ) (a) SDS ( $\square$ ) $0 \% 30^{\circ} \mathrm{C}$, ( $\square$ ) $0 \% 50^{\circ} \mathrm{C},(\triangle) 0.00130^{\circ} \mathrm{C},(\Delta) 0.00150^{\circ} \mathrm{C},(\bigcirc) 0.05 \% 30^{\circ} \mathrm{C},(\bullet) 0.05 \% 52^{\circ} \mathrm{C}$, and $(\nabla) 1 \% 30^{\circ} \mathrm{C}$ and Reduced viscosity for B-2 + surfactant mixtures in aqueous solutions at different temperatures (b) ( $\square) 0 \% 30^{\circ} \mathrm{C},(\boldsymbol{\square}) 0 \% 70^{\circ} \mathrm{C},(\triangle) 0.0005 \% 30^{\circ} \mathrm{C},(\boldsymbol{\Delta}) 0.0005 \% 68^{\circ} \mathrm{C},(\bigcirc) 0.05 \%$ $30^{\circ} \mathrm{C},(\bullet) 0.05 \% 71^{\circ} \mathrm{C}$, and $(\nabla) 1 \% 30^{\circ} \mathrm{C}$. Line represents fitted values.

characterized by low $[\eta]$ values at $30^{\circ} \mathrm{C}$ as compared to the B-1 containing mixtures. These trends are rationalized by considering the following factors. The More hydrophilic the copolymer-hydrocarbon surfactant mixture complexes, the more would be the hydrodynamic volume that is $[\eta]$. At the same time, the overall magnitude of $[\eta]$ depends upon the number of copolymer molecules in the mixed system. Hence, the observed increase in $[\eta]$ at $30^{\circ} \mathrm{C}$ with the increase in surfactant amounts can be rationalized based on the first factor. Even though triblock B-2 itself has more hydrophilic character, its micelles get easily dissociated in the mixed systems; therefore, its mixtures have smaller $[\eta]$ over the diblock B-1. The observed large $[\eta]$ values at elevated temperatures in general can be explained by the fact that the number of copolymer molecules is considerable in spite of the destabilization effects by added surfactants.

\section{Conclusions}

The diblock $\mathrm{E}_{18} \mathrm{~B}_{9}$ and triblock $\mathrm{E}_{13} \mathrm{~B}_{10} \mathrm{E}_{13}$ are typical amphiphilic copolymers and their aqueous solutions display characteristic turbidity and cloud points. The copolymers associate into micellar structures, constituted by a dense hydrophobic core surrounded by flexible hydrophilic corona. The copolymer micelles grow into large ellipsoids with high association numbers at elevated temperatures due to dehydration. The addition of ionic surfactants SDS or DTAB both in unimeric or micellar forms leads to (i) increase of turbidity and cloud points, (ii) the formation of copolymer-surfactant complexes, (iii) dissociation of copolymer micelles, and (iv) suppression of copolymer micelle formation. Nonionic surfactant, TX-100, addition to copolymer micelles, however, favors the formation of mixed micelles but with the decreased proportion of copolymer molecules. As compared to the diblock copolymer, triblock $\mathrm{E}_{13} \mathrm{~B}_{10} \mathrm{E}_{13}$ copolymer has more $\mathrm{E}$ units attached at both the ends of the middle hydrophobic $B$ units, and, therefore, the E chains interact strongly with the surfactant molecules resulting easy dissolution of micelles of latter as compared to the former. The destabilization and suppression of copolymer micelles was also observed at elevated temperatures indicating that the repulsive head group interactions among copolymer-surfactant complexes are more dominant than the usual dehydration and shrinking of hydrophilic chains at high temperatures. The copolymersurfactant complexes are characterized by large intrinsic hydrodynamic viscosities and hence are hydrophilic in nature.

\section{Acknowledgment}

The authors thank the UGC-DAE Consortium for the financial support under a collaborative research Grant no. IUC/AO/MUM/CRS M-108/03/2581.

\section{References}

[1] M. Almgren, W. Brown, and S. Hvidt, "Self-aggregation and phase behavior of poly(ethylene oxide)-poly(propylene oxide)-poly(ethylene oxide) block copolymers in aqueous solution," Colloid \& Polymer Science, vol. 273, no. 1, pp. 2-15, 1995.

[2] H. Altinok, S. K. Nixon, P. A. Gorry et al., "Micellisation and gelation of diblock copolymers of ethylene oxide and propylene oxide in aqueous solution, the effect of P-block length," Colloids and Surfaces B, vol. 16, no. 1-4, pp. 73-91, 1999. 
[3] H. Altinok, G. E. Yu, S. K. Nixon, P. A. Gorry, D. Attwood, and C. Booth, "Effect of block architecture on the self-assembly of copolymers of ethylene oxide and propylene oxide in aqueous solution," Langmuir, vol. 13, no. 22, pp. 5837-5848, 1997.

[4] V. M. Nace, "Contrasts in the surface activity of polyoxypropylene and polyoxybutylene-based block copolymer surfactants," Journal of the American Oil Chemists' Society, vol. 73, no. 1, pp. $1-8,1996$.

[5] L. Yang, A. D. Bedells, D. Attwood, and C. Booth, "Association and surface properties of diblock and triblock copoly(oxyethylene/oxypropylene/oxyethylene)s," Journal of the Chemical Society, Faraday Transactions, vol. 88, no. 10, pp. 1447-1452, 1992.

[6] Z. Yang, E. Pousia, F. Heatley et al., "Solubilization of alkylcyanobiphenyls in aqueous micellar solutions of a diblock copolymer of propylene oxide and ethylene oxide," Langmuir, vol. 17, no. 7, pp. 2106-2111, 2001.

[7] F. Heatley, G. E. Yu, W. B. Sun, E. J. Pywell, R. H. Mobbs, and C. Booth, "Triad sequence assignment of the 13C-NMR spectra of copolymers of ethylene oxide and 1,2-butylene oxide," European Polymer Journal, vol. 26, no. 5, pp. 583-592, 1990.

[8] V. M. Nace, R. H. Whitmarsh, and M. W. Edens, "Effects and measurements of polyoxyethylene block length in polyoxyethylene-polyoxybutylene copolymers," Journal of the American Oil Chemists' Society, vol. 71, no. 7, pp. 777-781, 1994.

[9] Dow Chemical Co, "Freeport, TX, B - Series Polyglycols, Butylene Oxide /Ethylene Oxide Block Copolymers," Technical Literature, 1994.

[10] Z. Yang, S. Pickard, N. J. Deng, R. J. Barlow, D. Attwood, and C. Booth, "Effect of block structure on the micellization and gelation of aqueous solutions of copolymers of ethylene oxide and butylene oxide," Macromolecules, vol. 27, no. 9, pp. 23712379, 1994.

[11] Y. W. Yang, N. J. Deng, G. E. Yu, Z. K. Zhou, D. Attwood, and C. Booth, "Micellization of diblock and triblock copolymers in aqueous solution. New results for oxyethylene/ oxybutylene copolymers E38B12 and E21B1121. Comparison of oxyethylene/oxybutylene, Oxyethylene/oxypropylene, and oxyethylene/alkyl systems," Langmuir, vol. 11, no. 12, pp. 4703-4711, 1995.

[12] G. E. Yu, Y. W. Yang, Z. Yang, D. Attwood, C. Booth, and V. M. Nace, "Association of diblock and triblock copolymers of ethylene oxide and butylene oxide in aqueous solution," Langmuir, vol. 12, no. 14, pp. 3404-3412, 1996.

[13] Z. Yang, Y. W. Yang, Z. K. Zhou, D. Attwood, and C. Booth, "Cooperative association of diblock and triblock copolymers in aqueous solution: a study of mixed micelles of block-copoly(oxyethylene/oxybutylene) and blockcopoly(oxybutylene/oxyethylene/oxybutylene)," Journal of the Chemical Society - Faraday Transactions, vol. 92, no. 2, pp. 257265, 1996.

[14] G. E. Yu, D. Mistry, S. Ludhera, F. Heatley, D. Attwood, and C. Booth, "Association and surface properties of tapered statistical copolymers of ethylene oxide and butylene oxide in water," Journal of the Chemical Society - Faraday Transactions, vol. 93, no. 18, pp. 3383-3390, 1997.

[15] A. Kelarakis, V. Havredaki, G. E. Yu, L. Derici, and C. Booth, "Temperature dependences of the critical micelle concentrations of diblock oxyethylene/oxybutylene copolymers. A case of athermal micellization," Macromolecules, vol. 31, no. 3, pp. 944-946, 1998.
[16] C. Chaibundit, S. M. Mai, F. Heatley, and C. Booth, "Association properties of triblock copolymers in aqueous solution: copolymers of ethylene oxide and 1,2-butylene oxide with long E-blocks," Langmuir, vol. 16, no. 24, pp. 9645-9652, 2000.

[17] A. D. Bedells, R. M. Arafeh, Z. Yang et al., "Micellisation of diblock copoly(oxyethylene/oxybutylene) in aqueous solution," Journal of the Chemical Society, Faraday Transactions, vol. 89, no. 8, pp. 1235-1242, 1993.

[18] Y. Z. Luo, C. V. Nicholas, D. Attwood, J. H. Collett, C. Price, and C. Booth, "Micellisation and gelation of block-copoly(oxyethylene/oxybutylene/oxyethylene) E58 B17 E58," Colloid \& Polymer Science, vol. 270, no. 11, pp. 1094-1105, 1992.

[19] Y. Z. Luo, C. V. Nicholas, D. Attwood et al., "Block-Copoly(oxyethylene/oxybutylene/oxyethylene), E40B15E40, in aqueous solution: Micellisation, gelation and drug release," Journal of the Chemical Society, Faraday Transactions, vol. 89, no. 3, pp. 539-546, 1993.

[20] L. Derici, S. Ledger, S. M. Mai, C. Booth, I. W. Hamley, and J. S. Pedersen, "Micelles and gels of oxyethylene-oxybutylene diblock copolymers in aqueous solution: the effect of oxyethylene-block length," Physical Chemistry Chemical Physics, vol. 1, no. 11, pp. 2773-2785, 1999.

[21] I. W. Hamley, J. S. Pedersen, C. Booth, and V. M. Nace, "A small-angle neutron scattering study of spherical and wormlike micelles formed by poly(oxyethylene)-based diblock copolymers," Langmuir, vol. 17, no. 20, pp. 6386-6388, 2001.

[22] P. Alexandridis, "Amphiphilic copolymers and their applications," Current Opinion in Colloid \& Interface Science, vol. 1, no. 4, pp. 490-501, 1996.

[23] N. V. Sastry and H. Hoffmann, "Interaction of amphiphilic block copolymer micelles with surfactants," Colloids and Surfaces A, vol. 250, no. 1-3, pp. 247-261, 2004.

[24] T. Thurn, S. Couderc, J. Sidhu et al., "Study of mixed micelles and interaction parameters for ABA triblock copolymers of the type $\mathrm{EO}_{m}-\mathrm{PO}_{n}-\mathrm{EO}_{m}$ and ionic surfactants: equilibrium and structure," Langmuir, vol. 18, no. 24, pp. 9267-9275, 2002.

[25] S. Couderc, Y. Li, D. M. Bloor, J. F. Holzwarth, and E. Wyn-Jones, "Interaction between the nonionic surfactant hexaethylene glycol mono- $n$-dodecyl ether $\left(\mathrm{C}_{12} \mathrm{EO}_{6}\right)$ and the surface active nonionic ABA block copolymer pluronic F127 $\left(\mathrm{EO}_{97} \mathrm{PO}_{69} \mathrm{EO}_{97}\right)$ - formation of mixed micelles studied using isothermal titration calorimetry and differential scanning calorimetry," Langmuir, vol. 17, no. 16, pp. 4818-4824, 2001.

[26] S. Couderc-Azouani, J. Sidhu, T. Thurn et al., "Binding of sodium dodecyl sulfate and hexaethylene glycol mono-ndodecyl ether to the block copolymer L64: electromotive force, microcalorimetry, surface tension, and small angle neutron scattering investigations of mixed micelles and polymer/micellar surfactant complexes," Langmuir, vol. 21, no. 22, pp. 10197-10208, 2005.

[27] J. Mata, T. Joshi, D. Varade, G. Ghosh, and P. Bahadur, "Aggregation behavior of a PEO-PPO-PEO block copolymer + ionic surfactants mixed systems in water and aqueous salt solutions," Colloids and Surfaces A, vol. 247, no. 1-3, pp. 1-7, 2004.

[28] E. M. S. Azzam, "The synergism effect between sodium dodecylbenzene sulfonate and a block copolymer in aqueous solution," Journal of Surfactants and Detergents, vol. 10, no. 1, pp. 13-17, 2007.

[29] A. Kelarakis, V. Castelletto, M. J. Krysmann, V. Havredaki, K. Viras, and I. W. Hamley, "Polymer-surfactant vesicular complexes in aqueous medium," Langmuir, vol. 24, no. 8, pp. 3767-3772, 2008. 
[30] A. Kelarakis, C. Chaibundit, M. J. Krysmann, V. Havredaki, K. Viras, and I. W. Hamley, "Interactions of an anionic surfactant with poly(oxyalkylene) copolymers in aqueous solution," Journal of Colloid and Interface Science, vol. 330, no. 1, pp. 67-72, 2009.

[31] S. S. Soni, N. V. Sastry, J. George, and H. B. Bohidar, "Surface active and association behavior of oxybutylene-oxyethylene and oxyethylene-oxybutylene-oxyethylene copolymers in aqueous solutions," Langmuir, vol. 19, no. 11, pp. 4597-4603, 2003.

[32] S. S. Soni, N. V. Sastry, A. K. Patra, J. V. Joshi, and P. S. Goyal, "Surface activity, SANS, and viscosity studies in aqueous solutions of oxyethylene and oxybutylene Di- and triblock copolymers," Journal of Physical Chemistry B, vol. 106, no. 50, pp. 13069-13077, 2002.

[33] S. H. Chen, "Small angle neutron scattering studies of the structure and interaction in micellar and microemulsion systems," Annual Review Physical Chemistry, vol. 37, pp. 351399, 1986.

[34] S. H. Chen and T. L. Lin, Methods of Experimental Physics, vol. 23B, Academic Press, New York, NY, USA, 1987.

[35] J. B. Hayter and J. Penfold, "Determination of micelle structure and charge by neutron small-angle scattering," Colloid \& Polymer Science, vol. 261, no. 12, pp. 1022-1030, 1983.

[36] J. B. Hayter and J. Penfold, "An analytic structure factor for macro ion solutions," Molecular Physics, vol. 42, pp. 109-118, 1981.

[37] J. B. Hayter and J. Penfold, "Self-consistent structural and dynamic study of concentrated micelle solutions," Journal of the Chemical Society, Faraday Transactions 1, vol. 77, no. 8, pp. 1851-1863, 1981.

[38] A. Guinier and G. Fournet, Small Angle Scattering of X-Rays, Wiley, New York, NY, USA, 1955.

[39] J. K. Percus and G. J. Yevick, "Analysis of classical statistical mechanics by means of collective coordinates," Physical Review, vol. 110, no. 1, pp. 1-13, 1958.

[40] K. Mortensen and J. S. Pedersen, "Structural study on the micelle formation of poly(ethylene oxide)-poly(propylene oxide)-poly(ethylene oxide) triblock copolymer in aqueous solution," Macromolecules, vol. 26, no. 4, pp. 805-812, 1993.

[41] N. W. Ashcroft and J. Lekner, "Structure and resistivity of liquid metals," Physical Review, vol. 145, no. 1, pp. 83-90, 1966.

[42] D. J. Kinning and E. L. Thomas, "Hard-sphere interactions between spherical domains in diblock copolymers," Macromolecules, vol. 17, no. 9, pp. 1712-1718, 1984.

[43] N. V. Sastry, S. H. Punjabi, V. K. Aswal, and P. S. Goyal, "Small angle neutron scattering and viscosity measurements on silicone-, ionic and nonionic surfactant mixed systems in aqueous solutions," Journal of Dispersion Science and Technology. In press.

[44] K. Mortensen and Y. Talmon, "Cryo-TEM and SANS microstructural study of pluronic polymer solutions," Macromolecules, vol. 28, no. 26, pp. 8829-8834, 1995.

[45] N. J. Jain, V. K. Aswal, P. S. Goyal, and P. Bahadur, "Micellar structure of an ethylene oxide-propylene oxide block copolymer: a small-angle neutron scattering study," Journal of Physical Chemistry B, vol. 102, no. 43, pp. 8452-8458, 1998. 

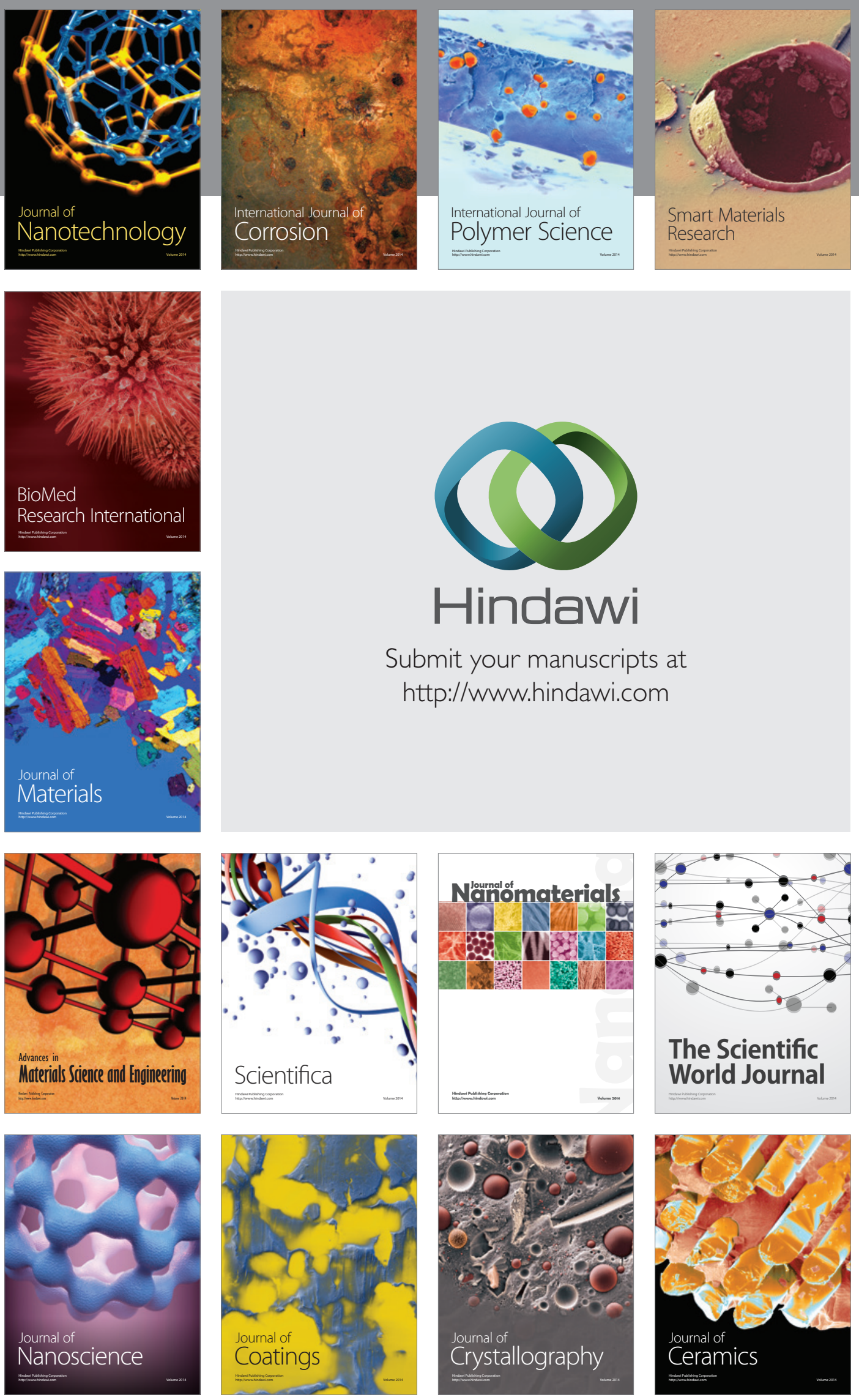

The Scientific World Journal

Submit your manuscripts at

http://www.hindawi.com

\section{World Journal}

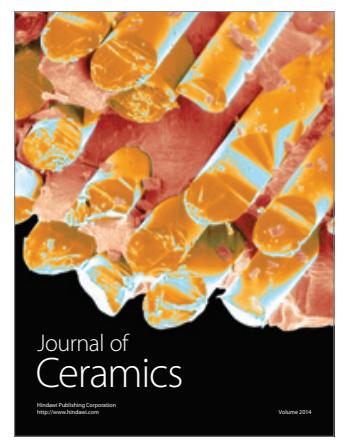

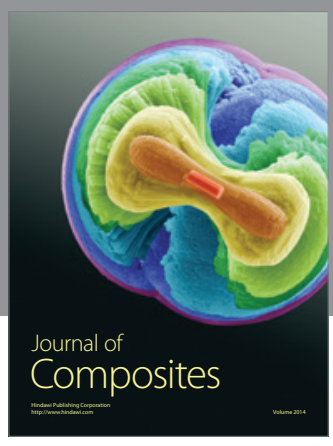
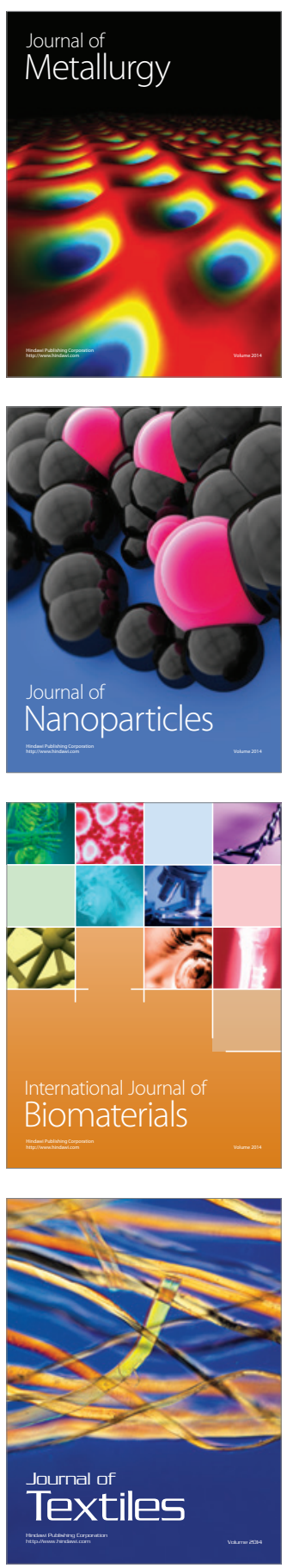